\title{
Facilitating Transdisciplinary Research in an Evolving Approach to Science
}

\author{
Fen Hunt ${ }^{1}$, Suzanne Thornsbury ${ }^{2}$ \\ ${ }^{1}$ USDA National Institute of Food and Agriculture, Washington DC, USA \\ ${ }^{2}$ USDA Economic Research Service, Washington DC, USA \\ Email: fhunt@nifa.usda.gov, sthornsbury@ers.usda.gov
}

Received 28 February 2014; revised 2 April 2014; accepted 10 April 2014

Copyright (C) 2014 by authors and Scientific Research Publishing Inc.

This work is licensed under the Creative Commons Attribution International License (CC BY). http://creativecommons.org/licenses/by/4.0/

(c) (i) Open Access

\begin{abstract}
Transdisciplinary research is changing the way research is conducted and supported by incorporating linkages between disciplinary fields, across geographic boundaries, and among scientists and broader societal stakeholder groups. There is a compelling opportunity and important role for social scientists to participate in both transdisciplinary projects addressing societal challenge issues and in research projects focused on the development of transdisciplinary project methodology and management. A shift in approach to scientific inquiry requires adjustments in institutional support structures as well as individual research projects and specific programs. US funding agencies, including the National Institute of Food and Agriculture (NIFA) have clearly built transdisciplinarity into their portfolio of research programs.
\end{abstract}

\section{Keywords}

Scientific Method; Transdisciplinary; Social Science; Research Funding

\section{Introduction}

The concept of transformative science is changing the way research is conducted, supported, and applied to solve grand societal problems. The conversion of scientific discovery into applied knowledge is increasingly recognized as what leads to lasting (i.e., transformative) impact [1]. Impetus for such a shift has come largely from outside conventional science as society faces complex issues that cannot be identified or addressed within the confines of a traditional disciplinary approach.

For example, reduction in water or air pollution is difficult to effectively address through research focused on a single discipline or geographic area. Likewise, issues of global (or national or regional) hunger involve physical, biological, economic, and social factors that must be addressed jointly for impactful progress to occur. The 
literature often characterizes these issues as "wicked" or "super-wicked" problems [2] [3]. Consequently, scientific inquiries are more frequently integrating basic with applied knowledge and extending across disciplinary and geographic boundaries [4].

One needs to look no further than the increased emphasis on regional collaboration in scientific research as evidence of the growing focus on societal issues that cannot be constrained by boundaries of geography of traditional disciplines. Regional science has long had a focus on disciplinary boundaries [5], albeit typically disciplines under the social science umbrella, and incorporating contributions from multiple disciplines in research [6]. The role of spatial heterogeneity is another central theme across many regional science studies.

A shift in approach to scientific inquiry is rarely (if ever) linear and ultimately requires adjustments in institutional support structures as well as individual research projects and specific programs. Numerous articles have documented challenges to overcoming institutional research structures designed to support single-discipline or single-investigator scientific inquiry ${ }^{1}$. The objective of this paper is to highlight positive adjustments made by US research funding agencies, specifically USDA's National Institute of Food and Agriculture (NIFA), to facilitate transformative research, in particular, progress towards inclusion of social science disciplines in transdisciplinary projects within the broad portfolio of funding support.

\section{A Shift in Scientific Approach}

While the concept of collaboration among researchers is not new, there have been significant changes in both the philosophy and delivery of cross-boundary projects in recent years. Even the language of scientific inquiry has evolved; moving from multipdisciplinary to interdisciplinary to trandisciplinary as a description of how researchers interact. Multidisciplinary research focuses on additive impacts where scientists work independently within their own disciplinary fields on a common topic and then come together to compile results at the end ${ }^{2}$. Projects generally do not include a focus on alternative ways to combine data or the input for more integrative solutions.

Interdisciplinary research typically involves greater dialogue and collaboration among scientists addressing issues across disciplines over the course of a project. Inter- and transdisciplinary approaches are not necessarily exclusive, and at times the terms have been used interchangeably to emphasize efforts designed to identify, capitalize, and leverage expertise from multiple disciplines ${ }^{3}$. As a distinguishing feature, transdisciplinary research further blends disciplinary boundaries to achieve integrative collaboration.

The essence of transdisciplinary research requires a synthesis of ideas and methods among researchers with emphasis on a format for conversations and connections that lead to new knowledge. Participants step outside conceptual, theoretical, and methodological confines of their own discipline and develop a shared approach to address the problem under consideration. Scholars involved in transdisciplinary projects must be willing to transcend and integrate disciplinary paradigms with the goal of finding a unity of knowledge beyond individual fields of study [7]. A fundamental element of transdisciplinary research is that collaboration leads to new ways of framing, understanding, and addressing issues; and knowledge of a single science or societal field is not enough [8] [9]. Projects “....integrate information, data, techniques, tools, perspectives, concepts, and/or theories from two or more disciplines or bodies of specialized knowledge to advance fundamental understanding or to solve problems whose solutions are beyond the scope of a single discipline or field of research practice" [10].

Reference [11] identifies inclusion of non-academic participants as an additional feature that would distinguish transdisciplinary from interdisciplinary projects (Figure 1). Stakeholders—or users—of scientific output are included as active participants in the research process, stimulating further scientific inquiries so as to make tangible impacts on society [14]. Such inclusion is not a new idea; indeed, it can be considered as the foundation of extension programs and participatory (or community-based) research (e.g., [15]). Including a broad group of stakeholders throughout the research process is akin to extending the peer group that has input in research framing and project evaluation.

Although not required, many transdisciplinary projects tend to have large groups of participants composed of researchers and stakeholders across multiple locations. Team members typically collaborate over extended pe-

\footnotetext{
${ }^{1}$ See, for example the series of workshops and articles sponsored by National Research Council Committee on the Science of Team Science (http://sites.nationalacademies.org/dbasse/bbcss/currentprojects/dbasse 080231).

${ }^{2} \mathrm{An}$ analogy that has been used in the literature is parallel play [11] [12].

${ }^{3}$ Multitaxon research is a term that has been used to represent collaborative research across fields within a common discipline [13].
} 


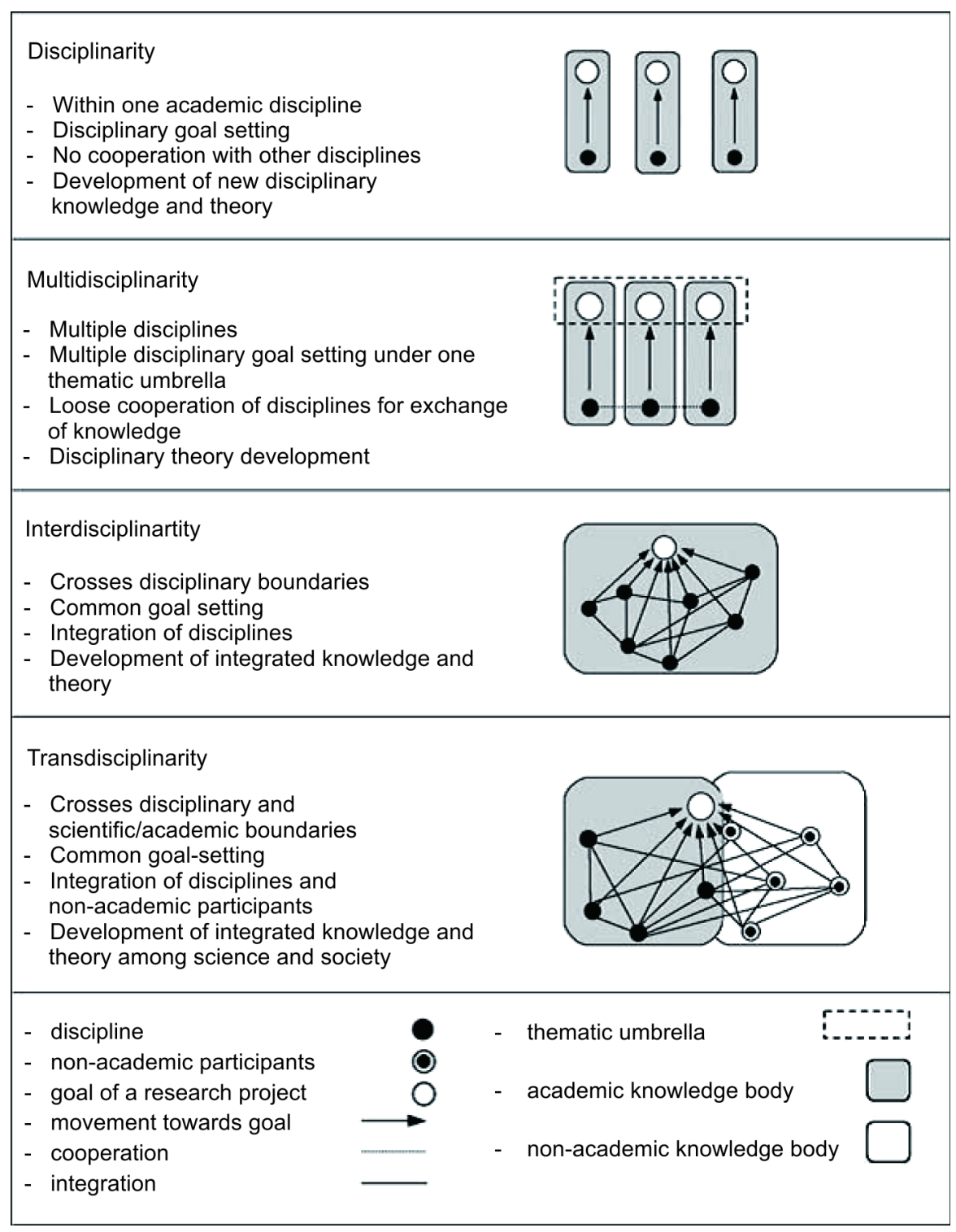

Figure 1. Overview of research concepts. Source: Tress, Tress, and Fry, 2004 (reprinted by permission).

riods of time (e.g., 5+ years) to frame researchable questions and develop novel conceptual frameworks and methods with the potential to produce transcendent theoretical approaches. Project leadership is complex and requires skills well-beyond single-discipline research and publication [16] [17]. With this scientific approach, a significant time commitment is often required to build common language and understanding, even around topics that might be implicitly understood within a single discipline (e.g., terminology, methodological or cultural traditions) [18] [19].

Definition of the research project itself becomes more complex and must clearly identify what is to be gained beyond additive results from single-discipline studies [20]. There is a need to balance broad inclusiveness of disciplines and individual perspectives with project tractability [21]. Likewise, determining evaluation criteria often becomes a part of the research process [22] and is likely to be very different than the review criteria applied to traditional research. Transdisciplinary projects are most often constructed to address complex (or wicked) problems that are difficult or impossible to "solve". Rather, progress is made towards an outcome that can be assessed as better or worse given the judgment of multiple stakeholders [2].

Notwithstanding the need for basic and disciplinary research and knowledge, a transdisciplinary approach can 
often be used to address highly complex societal issues. Similar to the shift to greater complexity in societal issues, the shift in scientific approach to more complicated transdisciplinary projects is not without challenges. A 2007 review of integration efforts in three National Science Foundation (NSF) program areas found that "enthusiasm for collaboration is necessary but insufficient on its own” [23]. Significant adjustment is required at the project management, individual, institutional, and research funding levels_-all of which have developed in a world of distinct scientific disciplines and geographic boundaries.

\section{Facilitating the Shift through Funding Agency Programs}

An important component of any scientific project is access to funding. The administration of funding programs (or portfolios) influences individual research project design through priorities, foci, and other requirements in the request-for-applications (RFA) and through project oversight once funding awards have been made. To facilitate the move towards transformative science, US funding agencies have increasingly built transdisciplinary research projects into their program portfolios.

Early attempts at implementing transdisciplinary approaches to problem solving developed within the medical community. Since 1947, medical doctors and health workers at the World Health Organization (WHO) noted that both medical and socio-cultural factors are important to delivery of effective health care, especially in cross-cultural settings. Despite this recognition, social scientists were rarely full-fledged members of the health team in those early years. Not only were social science proposals for grant support reviewed primarily by medical doctors, but the role of social scientists and their research methods were also little understood or appreciated [24]. During the 1970s, through efforts of the WHO Social and Economic Research (SER) Steering Committee and insistence of external donors (e.g., Scandinavian countries and the World Bank), broader interdisciplinary teams were formed and methods for research analysis incorporated greater socio-cultural assessment. The first World Congress of Transdisciplinarity was held in Portugal in 1994 and UNESCO sponsored a global Symposium on Transdisciplinarity in 1997. A driving topical focus of both meetings was complex issues associated with globalization.

More recently, understanding and acceptance of boundary-crossing approaches to addressing societal issues have gained increased attention well beyond the health profession. In the US, both the National Institute of Health (NIH) and NSF have increasingly promoted and funded transdisciplinary research to focus on broad societal issues. Three examples are provided below.

A 2002 report released by The International Agency for Research on Cancer estimated that as much as one-third of certain cancers might be attributable to a combination of increased body weight and lack of physical activity; yet in 2004, NIH noted that cancer research was still largely focused on single-cancer prevention factors without consideration of socio-environmental impacts [25]. The 2004 NIH Obesity Research Task Force then released a Strategic Plan setting new priorities, which included preventing and treating obesity through lifestyle modification, breaking the link between obesity and associated health conditions, and focusing on cross-cutting research (e.g., health disparities and behavior, or transitional research). In response, The National Cancer Institute (NCI) initiated the 5-year, \$54 million Transdisciplinary Research on Energetics and Cancer (TREC) in $2005^{4}$. Four research centers and one coordination center were funded to focus on interactions among social, behavioral, and biological sciences to address obesity, physical inactivity, and poor diet related to cancer risk.

A more recent assessment of NIH programs identifies movements towards transdisciplinary research, especially in the life sciences, where collaboration across disciplines is becoming the norm as an important factor [26]. Advances in one field influence research in another and emerging technologies are frequently relevant across different fields. A radical restructure was proposed as the way to address the systematic concerns of the world's biggest funder of biomedical research. Rather than rewarding maximum knowledge production, research funding would be targeted towards success at producing cost-effective improvements for society.

A second example of movement towards transdisciplinary research by a funding agency is the Long-term Ecological Research (LTER) Network established in 1980 by NSF to study ecological processes over broad temporal and spatial scales. The LTER Network was designed to move science beyond a single-discrete geo-

\footnotetext{
${ }^{4}$ Other NCI multidisciplinary and transdisciplinary initiatives include the Transdisciplinary Tobacco Use Research Centers, Centers of Excellence in Cancer Communication Research, Breast Cancer Surveillance Consortium, and National Collaborative on Childhood Obesity Research.
} 
graphic site; however, it did not initially expand beyond classic disciplinary boundaries. Social scientists joined the LTER Network in 1998, yet input was limited [27]. Despite having convened a series of meetings and workshops that elevated efforts of integrating ecologists and social scientists, a follow-up meeting of LTER social scientists in 2005 showed that much was still to be done [28]. While progress was evident, challenges remained to integrative research and synthesis.

Recommendations from the LTER Social Science Committee included establishing long-term base funding opportunities for expanding disciplinary-based integrative research and advancing the contribution of social sciences within the long-term program. A 30-year review found that “...many LTER researchers have recognized the dynamic link between human and ecosystems, and have included social science components in their research program" [29]. Not surprisingly, success in integrating across disciplines varied among projects and, in the case of LTER, social sciences had played a more central role in shaping the research programs in urban sites. Further, the report noted that "though there is a real need to increase integrated research across the natural and social sciences to effectively address human-ecosystem interactions, it is not clear that LTER is well suited to contribute to fundamental advances in the social sciences...”.

Another NSF program, Division of Biological Infrastructure (DBI), funded the National Socio-Environmental Synthesis Center (SESYNC) in 2011 to stimulate research, education and outreach at the interface of the biological, geological, and social sciences. DBI had previously funded a number of synthesis centers with a purpose of bringing together research from different disciplines within natural sciences. SESYNC was broader and the first in DBI to integrate natural and social sciences. The center stresses bottom-up, discovery-driven research, co-developing science questions with policy groups, and commingling social-and natural-science perspectives to refine and address the questions. Focusing on what motivates the priority questions and who are engaged in the process of identifying those priorities, this type of actionable science triggers new relationships among scientists, fosters new data and methods, and stimulates the most creative impulses of research community [30].

\section{Evolution of Scientific Approach at USDA National Institute of Food and Agriculture}

The National Institute of Food and Agriculture ${ }^{5}$ invests in science to help solve critical issues in US agriculture and food systems through federal funding and leadership for extramural research, education, and extension programs. Similar to programs at other funding agencies, NIFA has increasingly facilitated transdisciplinary research and the inclusion of social sciences as part of the agency's program portfolio.

The National Research Council's (NRC) 2003 comprehensive review of the US agricultural research portfolio provided a national vision of agricultural research that highlighted the need for a more comprehensive approach.

"Agricultural research will support agriculture as a positive economic, social, and environmental force... include...other benefits as enhanced public health, environmental services, rural amenities, and community well-being...Agricultural research will engage relevant biophysical and socioeconomic disciplines in a systems approach..." [31].

The report emphasized that US agricultural research should be conducted with an increased understanding and awareness of how problems and solutions are interconnected globally. Five major challenges (i.e. globalization of the food economy; emerging pathogens and other hazards in the food-supply chain; enhancing human health through nutrition; improving environmental stewardship; and improving quality of life in rural communities) were identified where the intersection of cutting-edge science with stakeholder needs provided compelling opportunities for research frontiers in the 21st century.

These challenge areas clearly crossed disciplinary and geographic boundaries that would require large and long-term research commitments. At that time NIFA competitive funding programs and internal structure were largely designed around more traditional single-disciplinary research lines. Recognition of the evolution in scientific approach and external forces were drivers of change, NIFA began to expand its program portfolios to include long-term, large-scale projects towards a multidisciplinary, interdisciplinary, and eventually transdiscip-

${ }^{5}$ Prior to October 2010, the Cooperative State Research, Education, and Extension Service (CSREES). In the 2008 Farm Bill, Congress mandated a name change to NIFA (effective October 1, 2010) to draw attention to the agency's role as the major funding organization for national agricultural and food systems research (an equivalent role to NIH and NSF). 
linary framework. However, as an institution, NIFA had to undertake a series of adjustments to not only signal the need for changes in scientific approach, but also implement the processes in project selections as well as post-award management for ensuring accountability.

In 2004, in addition to single disciplinary research programs, NIFA moved to extend research programs across geographic barriers through Coordinated Agricultural Projects (CAPs) under the then National Research Initiative (NRI) program (hereafter, NRI-CAPs). The goal was to strengthen and advance both fundamental and applied science in support of agricultural and food systems. NRI-CAPs were community-based and applied research projects, designed to promote well-coordinated, long-term (i.e., 4 years), and larger scale collaboration. With interactions among research, teaching, and/or extension programs (often referred to as "integrated" programs), the goal of NRI-CAPs was to deliver science-based knowledge to users, including the general public, enabling informed and practical decisions.

Early NRI-CAPs were largely multidisciplinary in nature, with the major integration taking place across university functions (i.e. research, teaching, and outreach). Collaboration among multiple disciplines was, at best, between basic and applied research to transfer knowledge to end users. Focus was determined by traditional definitions of agricultural science (i.e. mostly commodity-based) rather than societal issues. For example, the Rice CAP was funded to bridge the gap between rice genome researchers (fundamental research) and plant breeders (applied research). Accomplishments include the use of molecular markers in variety development programs among all US public rice breeding programs to enable a more economic transfer of marker technology to plant breeders [32]. In addition, the project incorporated the USDA Agricultural Research Service Mid-South Area (MSA) Genomics Laboratory. Partnership with the MSA lab not only synergized knowledge and leveraged resources, but also led to the further development of novel genetic resources.

Over the years, in response to the complex nature of contemporary issues facing agriculture, natural resources, and the environment and to make impactful results on the ground, NIFA emphasized and increased support for stakeholder engagement. Even as the early NRI-CAP projects were underway, NIFA sponsored a workshop, "Long-Term Agricultural Research (LTAR): Research, Education, and Extension" in 2006 to help plan and strategize for a competitive program that would support science to better understand the interrelationship between agriculture and ecosystems in achieving long-term sustainability. Workshop participants included nationally renowned scholars with expertise ranging from ecology, biology, plant or soil science, and economics. The report encouraged NIFA to foster long-term, site-based research allowing diverse, non-traditional research collaborations to form more readily across academic disciplines and with non-academic communities [4]. Instead of a single discrete site, members of the workshop stressed the need for examining effects and interactions of the agro-ecosystem at multiple spatial and temporal scales. Two of six goals identified for each research site were socioeconomic aspects (i.e., community vitality and the social and behavioral constraints to change) of the agro-ecosystems.

The 2008 Farm Bill that mandated agency reorganization was a key turning point for NIFA programs to move towards a transdisciplinary approach. In addition to supporting basic or foundational science, challenge-area programs were directed towards fewer, larger, longer-term projects to fully encompass the nature and complexity of identified societal problems, guide multiple facets of science in a more collaborative and interdependent manner, and demonstrate valid, reliable, and tangible outputs and impact.

The 2008 Farm Bill also authorized a congressionally mandated program to provide research support specifically for the critical needs of the specialty crop industry. The resulting Specialty Crop Research Initiative (SCRI) request for applications (RFA) listed five project types, including CAPs. SCRI strongly encouraged applicants to propose a systems approach for solving problems ${ }^{6}$. Within the SCRI program, transdisciplinarity was defined as a multi-discipline approach that brings biological and physical scientists together with economists and other social scientists to address challenges in a holistic manner [33]. SCRI awarded more than 20 CAPs between 2008 and 2012. Each CAP includes a mix of social and physical components, a systems approach for solving problems, and a stakeholder advisory committee.

The extent of actual integration beyond a multi-disciplinary framework (i.e., parallel play) among disciplines varies widely between individual teams. For example, one integrated project, Precision Irrigation and Nutrient

\footnotetext{
${ }^{6}$ The RFA defines a systems approach as "any process of estimating or inferring how local policies, actions, or changes influence the state of the neighboring universe. It is a framework that is based on the belief that the component parts of a system can best be understood in the context of relationships with each other and with other systems, rather than in isolation. The only way to fully understand why a problem or element occurs and persists is to understand the part in relation to the whole” [33].
} 
Management for Nursery, Greenhouse, and Green Roof Systems, includes not only academic research and extension scientists in a variety of disciplines from across the US, but also industry scientists. Researchers actively collaborate with commercial growers using production areas as test environments. On-site technology experiments help growers automate irrigation based on the actual water needs of the nursery crops to increase water use efficiency, shorten the crop cycle, reduce disease risk and improve crop and flower quality. The technology has been implemented by commercial growers who are reporting improved economic outcomes.

Movement towards a transdisciplinary approach was incorporated into some (but not all) of the longer-running NIFA programs. In 2009, the Agriculture Food Research Initiative (AFRI) initiated the Sustainable Agroecosystems Science Long-Term Agroecosystem Program: Proof of Concept (SAS-LTAP), which incorporated transdisciplinary concepts ${ }^{7}$. A critical part of the program was to encourage extension faculty to establish a network of stakeholders (e.g. land managers and farmers) and connect them with researchers in collective and collaborative study of long-term processes and the coupled dynamics of ecological, production, and socio-economic systems. Stakeholder involvement was an important component of the transdisciplinary team. Despite a promising start, the program was short-lived as SAS-LTAP was eventually incorporated within another program as NIFA restructured AFRI.

During the same year, NRC released a major report, A New Biology for the 21st Century, which argued biological research was in the midst of a revolutionary change [34]. Societal challenges were identified as sustainable food production, protection of the environment, renewable energy, and improvement in human health. New Biology was defined as integration or reintegration of the many subdisciplines of biology or life sciences, and the integration of biologists with physicists, chemists, computer scientists, engineers, and mathematicians to create a research community with the capacity to address these societal challenges. The report encouraged a national research agenda defined by the issues science must address; letting the problems drive the science. To be successful, transformative approaches would be required in problem-focused, collaborative, cross-cutting, and interdisciplinary research through a coordinated effort to leverage research and development (R\&D) investments.

Despite progress in integrating fields within a discipline, integration of multiple disciplines-particularly across physical and social sciences—-was more challenging. NIFA hosted a workshop in July 2009 to develop strategic directions for a climate change program area, including mitigation and adaptation that would incorporate the concepts raised in the NRC report. Three goals were identified: 1) to build strong partnerships to develop and provide cutting-edge research programs; 2) to advance novel ideas to manage risk and benefit from new opportunities; and 3) to create innovative tools for communication and education. The workshop report highlights needs for coupled human-natural systems bringing together the natural sciences, engineering, mathematics, business, social and political sciences, economics, and education to provide the advanced models and management systems required to achieve these goals [35].

At least in part to facilitate integration among their own program leaders, over the same period NIFA undertook an internal reorganization and restructured into four institutes and one center: Institute of Bioenergy, Climate and Environment; Institute of Youth, Family, and Community; Institute of Food Safety and Nutrition; Institute of Food Production and Sustainability; and Center for International Programs. This change facilitated adjustments in the agency's flag-ship competitive program, AFRI, to reflect greater focus, scale, and impact on six grand societal challenges, among others: Food Security, Climate Variability and Change, Sustainable Bioenergy, Food Safety, Childhood Obesity Prevention, and Water for Agriculture; and institutionalized a multiple disciplinary-based team-approach to program development, implementation, as well as management.

In 2010, the White House identified science and technology priorities to include a clean energy future; understanding, adapting to and mitigating impacts of global climate change; and integrated ecosystem management (among others) [36]. Both the White House priorities and a second NRC report emphasized the necessity of a transformative approach that brought together multiple disciplines (social science, economics, biophysical) to address sustainability.

“ ...the sustainability of agriculture is not simply a question of science. Decisions about selecting among various alternative futures for agriculture and their attendant environmental, economic, and social goals

\footnotetext{
${ }^{7}$ The Agriculture and Food Research Initiative (AFRI) is the NIFA competitive grants program for funding research, education, and extension projects as well as integrated research. AFRI is the successor program to National Research Initiative and funds projects focused on societal challenges besides foundational (basic research) programs.
} 
emerge from an articulation of social aspirations, which falls within the realm of politics. It is through deliberative, democratic processes that the expression, discovery, transformation, and creation of social beliefs and policy preferences can occur...” [37].

Two years previously, NIFA had invited a panel of social scientists from academia, government, and the private sector to engage in a dialogue with the agency's executive leaders to identify the role of social science as a component of agency programs. In their report, the panel noted that many critical and emerging issues would not lend themselves to traditional research management and a new approach to framing issues and supporting projects with the appropriate knowledge, talent, and resources was needed [38]. Consensus views that emerged, included:

“...[NIFA] has both the opportunity and the responsibility to administer funds in the context of new frameworks, such as regional, national and international, as well as integrated problem-oriented approaches...

...[NIFA] has to continue to pioneer the process for bringing local, regional, and national concerns, as well as cross-disciplinary concerns, together for informing the research and education community and for identifying gaps and needs...”

To further the implementation of concepts highlighted in the aforementioned report, a second workshop with nationally renowned scholars from multiple disciplines gathered in Washington DC in May 2010 [39]. The purpose was to identify the role and unique contributions of social sciences to transdisciplinary research and to discuss effective strategies for NIFA to foster collaboration. Key recommendations emphasized the need for a new systems approach in applied scientific research and included:

- Successful collaboration is... problem-based scholarship, rather than requiring a pre-determined set of disciplines or fields;

- ...to be successful, a transdisciplinary project requires participants who are aware of the distinction between transdisciplinary and multidisciplinary research, and who are also strong in their respective disciplines, leading to a unity of knowledge beyond individual disciplines;

- ...Transdisciplinary cooperation should be incorporated in framing the problem, team leadership, and program management, as well as in the research/outreach/teaching components of a project. This will allow the team to address the nature and complexity of real-world problems, and lead to reliable outputs and impacts; and

- ...realize the importance of key stakeholders being actively engaged in meaningful ways from the beginning of project planning to the end as users of research results.

NIFA continued to focus on a transdisciplinary systems approach to help solve societal problems in the restructured 2010 AFRI programs. Within AFRI's eight programs, six focused on the grand societal challenges that had been identified. While each challenge area encompassed opportunities for smaller disciplinary-based research programs, it also included large-scale, multi-year, multi-state, and transdisciplinary CAPs, as well as other integrated research, education, and extension projects. For example, the Sustainable Bioenergy (SBE) Challenge Area sought to facilitate the establishment of regional systems for the sustainable production of bioenergy and biobased products. To accomplish this objective, the SBE Regional CAP project requires not only integrated research, education, and extension activities, but also a transdisciplinary approach where biomass suppliers and biorefinery companies are key stakeholders and partners actively engaged in the project.

In selecting projects for funding, NIFA not only invites multidisciplinary peer-review panels to objectively rank the applications, but also establishes a reverse-site visit process before finalizing project selections. During the reverse-site visit, representatives (including academia, industry, stakeholders, etc.) from highly ranked applications further elaborate the project and respond to specific questions about project management, demonstrating the capacity for transdisciplinary project success. Once projects are awarded, there are several levels of accountability that NIFA must oversee. For example, there is fiscal accountability, project team collaboration and management, project interaction with advisory board and stakeholders, project outputs, and outcomes. In general, CAPs are continuation awards. While NIFA makes 5-year funding commitment upfront, funding is awarded annually subject to satisfactory review of the annual report and project progress. Regular teleconferences between NIFA program leaders and project directors (PD) are the norm. Project team members attending annual program PD meeting is also required not only to share progress and knowledge discovery but also to get 
feedback from peers for enhancing project success.

For an agency that will typically commit substantial support to a long-term project, a priori determination of which projects will evolve successfully is especially challenging. Risks associated with project failure may increase, particularly when agencies are required to show concrete impacts in programmatic areas on an annual cycle for continued programmatic funding support. As this transformative approach continues to evolve, funding organizations may need to contend with the high costs and risks of transdisciplinary research, overcome challenges in adaptive management, yet continue their efforts and commitment to facilitating this type of systems approach for making tangible impact on the society.

\section{NIFA-Funded Projects}

To illustrate NIFA's on-going effort to facilitate transdisciplinary systems approach to science, we describe three specific projects that were funded in the Climate Variability and Change Challenge Area: 1) Regional Approaches to Climate Change-Pacific Northwest Agriculture (REACCH); 2) Climate Change, Mitigation, and Adaptation in Corn-based Cropping Systems (Sustainable Corn); and 3) Useful to Usable (U2U): Transforming Climate Variability and Change Information for Cereal Crop Producers.

As suggested in its title, REACCH takes a regional approach to enhance the sustainability of cereal production systems in northern Idaho, north central Oregon, and eastern Washington under ongoing and projected climate change scenarios while contributing to mitigation efforts by reducing emissions of greenhouse gasses [40]. There are eight objectives ranging from developing a conceptual and operational modeling framework, greenhouse gas monitoring, comparative assessment of alternative cropping systems, determining social and economic factors in the adoption of technology and management practices, to K-12 education, outreach, cyber-infrastructure, and data management.

Building collaboration and managing on-time progress of the project with a complex team of participants is no simple task and these activities are increasingly recognized as core components of NIFA-funded CAP projects. For example, a planning grant from NIFA SAS-LTAP with a subset of team members preceded REACCH. This provided an opportunity to develop team synergies and common understanding of the research goals and perspectives prior to proposal submission for the larger project. Project funding support includes hiring of a project manager to assist the PD for day-to-day administrative operations and facilitate team communication through regular teleconference, project website, and newsletters.

The Sustainable Corn CAP project also takes a regional approach to climate change, mitigation, and adaptation in corn-based production systems [41]. The goal of the project is to assess environmental, economic, and social impacts of long-term climate variability for long-term sustainability and productivity in corn-based crop management systems. Collaborators from 11 institutions in nine states include diverse expertise in environmental science, ecology, natural resource management, crop and soil science, plant science, agronomy, agricultural education, engineering, human and community resource development, economics, and sociology. The PD's expertise in social connection and human dimensions of natural resource management provides critical leadership in forming and facilitating such a diverse team. Selected accomplishments related to project design include creating a roadmap defining disciplinary and transdisciplinary project expectations and opportunities for becoming respective scholars as participants in this CAP project. The project's centralized database equipped team members with multi-site data used in interdisciplinary team discussions and analysis.

While not categorized as a CAP, U2U is nonetheless a regional, long-term, transdisciplinary project, encompassing nine institutions transforming useful climate mitigation and adaptation knowledge to usable information to stakeholders in twelve Midwestern states [42]. This project is led by a PD with expertise in the area of interaction between natural resource and social science. In its first year, U2U focused on building a research team to collaboratively frame the problem and research questions. The group expanded to include 50 researchers, extension educators, and students with expertise in climatology, agronomy, crop modeling, cyber-technology, economics, and social science. Project objectives include developing a knowledge base of potential biophysical and economic impacts related to climate change, understanding the use and value of climate information for decision making, determining effective methods for disseminating usable climate knowledge, and training future scientists. Results from producer and advisor surveys and focus groups as well as findings from crop modeling and economic case studies directly influence the development of effective decision support tools that are further evaluated and validated through implementation by producers in four pilot states. The project includes annual internal process evaluations on team-building, communication, collaboration, and project progress. 
As described above, all of these three large, long-term, well-coordinated transdisciplinary projects include stakeholders as an integral part of the research team. A particular challenge to funding organizations is how to provide incentives to, or account for, the relatively long preparatory periods required by large diverse research teams participating in transdisciplinary work. Communication and team-building, as well as problem-definition, project management, co-authorship, and evaluation criteria typically evolve simultaneously over an extended planning and throughout the project.

\section{Summary}

Transdisciplinary projects, including those from a number of NIFA programs, provide unique opportunities for scientific research to incorporate linkages between disciplinary fields, across geographic boundaries, and among scientists and broader societal stakeholder groups. Human and social components are an integral part of the research process from initial problem identification to evaluation of results; however, a shift in approach to scientific inquiry requires adjustments in institutional support structures as well as individual research projects and specific programs.

While individual researchers may have personal propensities and training that motivate them to pursue such projects in order to be successful, external incentives for participation must align. Scientists work within the context of their institutional environment, and most research environments remain structured around traditional disciplinary lines (i.e., university departments). Still academic institutions can create conducive or prohibitive cultures for transdisciplinary research within traditional departments or through broader reorganizations into interdisciplinary schools or centers that have taken place at some academic institutions (e.g., Arizona State University).

As the language and practice of scientific inquiry has shifted, funding agency programs have also evolved over time. Funding agencies can promote transdisciplinary research through specific grant program structures. As the complexity of societal problems continues to increase, US funding agencies, including the National Institute of Food and Agriculture (NIFA), have clearly built transdisciplinarity into their portfolio of research programs. Notwithstanding the value and contributions of basic and single-discipline research, transdisciplinary research has become a stimulating scientific approach to helping solve complex societal issues.

There is a compelling opportunity and important role for social scientists to participate both in transdisciplinary projects addressing societal challenge issues and in research projects focused on the development or assessment of transdisciplinary project methodology, management, and impact. The increased emphasis on regional collaboration in scientific research is evidence of the growing focus on societal issues that cannot be constrained by boundaries of geography of traditional disciplines. With a focus on human behaviors including response to incentives (positive and negative) and adaptability, social science will be at the core of designing, managing, implementing, and evaluating successful transdisciplinary research addressing current as well as future societal challenges.

\section{Acknowledgements}

The views in this paper do not necessarily represent those of the US Department of Agriculture, the National Institute of Food and Agriculture, or the Economic Research Service. The authors appreciate comments received on an earlier draft at the 51st Southern Regional Science Association Annual Meeting, Charlotte, NC, March 22-24, 2012.

\section{References}

[1] Jackson, R. (2011) Knowns, Unknowns, and Impacts, Presidential Address. Southern Regional Science Association, New Orleans. http://srsa.org/pdf/SRSA\%20Address2011.pdf

[2] Batie, S. (2008) Wicked Problems and Applied Economics. American Journal of Agricultural Economics, 90, 11761191. http://dx.doi.org/10.1111/j.1467-8276.2008.01202.x

[3] Lazarus, R. (2009) Super Wicked Problems and Climate Change: Restraining the Present to Liberate the Future. Cornell Law Review, 94, 1153-1234.

[4] Robertson, G.P., et al. (2008) Long-Term Agricultural Research: A Research, Education, and Extension Imperative. BioScience, 58, 640. http://dx.doi.org/10.1641/B580711 
[5] Cushing, B. (2011) Advancement of Knowledge: A Journey Through Space and Time. The Review of Regional Studies, 41, 73-80.

[6] Schaefer, P.V., Jackson, R.W. and Bukenya, J.O. (2011) Regional Science Reconsidered. The Review of Regional Studies, 41, 161-177.

[7] Pohl, C. (2010) From Transdiciplinarity to Transdisciplinary Research. Transdisciplinary Journal of Engineering and Science, 1, 74-83.

[8] Wiesmann, U., Hadorn, G., Hoffmann-Riem, H., Biber-Klemm, S., Grossenbacher, W., Joye, D., Pohl, C. and Zemp, E. (2008) Enhancing Transdisciplinary Research: A Synthesis in Fifteen Propositions. In: Hadorn, G., Hoffmann-Riem, H., Biber-Klemm, S., Grossenbacher-Mansuy, W., Joye, D., Pohl, C., Wiesmann, U., and Zemp E., Eds., Handbook of Transdisciplinary Research, Springer, Dordrecht. http://dx.doi.org/10.1007/978-1-4020-6699-3_29

[9] Rosenfield, P.L. (1992) The Potential of Transdisciplinary Research for Sustaining and Extending Linkages between the Health and Social Sciences. Social Science \& Medicine, 35, 1343-1357. http://dx.doi.org/10.1016/0277-9536(92)90038-R

[10] National Academy of Sciences (2004) Facilitating Interdisciplinary Research. The National Academies Press, Washington DC.

[11] Tress. G., Tress, B. and Fry, G. (2004) Clarifying Integrative Research Concepts in Landscape Ecology. Landscape Ecology, 20, 479-493. http://dx.doi.org/10.1007/s10980-004-3290-4

[12] Gray, B. (2008) Enhancing Transdisciplinary Research through Collaborative Leadership. American Journal of Preventative Medicine, 35, S124-S132. http://dx.doi.org/10.1016/j.amepre.2008.03.037

[13] Wake, M.H. (2008) Integrative Biology: Science for the 21st Century. BioScience, 58, 349-353. http://dx.doi.org/10.1641/B580410

[14] Van Kerkhoff, L. (2005) Strategic Integration: The Practical Politics of Integrated Research in Context. Journal of Research Practice, 1.

[15] Cornwall, A. and Jewkes, R. (1995) What Is Participatory Research? Social Science and Medicine, 41, 1667-1676. http://dx.doi.org/10.1016/0277-9536(95)00127-S

[16] Levinson, B. and Thornton, K.W. (2003) Managing Interdisciplinary Research: Lessons Learned from the EPA/NSF/ USDA Water and Watersheds Research Program. The First Interagency Conference on Research in the Watersheds, Benson. http://www.tucson.ars.ag.gov/ICRW/Proceedings/Levinson.pdf

[17] Youtie, J. and Corley, E. (2011) Federally Sponsored Multidisciplinary Research Centers: Learning, Evaluation, and Vicious Circles. Evaluation and Program Planning, 34, 13-20. http://dx.doi.org/10.1016/j.evalprogplan.2010.05.002

[18] Eigenbrode, S., et al. (2007) Employing Philosophical Dialogue in Collaborative Science. BioScience, 57, 55. http://dx.doi.org/10.1641/B570109

[19] Pohl. C. (2005) Transdisciplinary Collaboration in Environmental Research. Futures, 37, 1159-1178. http://dx.doi.org/10.1016/j.futures.2005.02.009

[20] Dovers, S. (2005) Clarifying the Imperative of Integration Research for Sustainable Environmental Management. Journal of Research Practice, 1. http://jrp.icaap.org/index.php/jrp/article/view/11/30

[21] Walter, A., Halgenberger, S., Wiek, A. and Scholz, R. (2007) Measuring Societal Effects of Transdisciplinary Research Projects: Design and Application of an Evaluation Method. Evaluation of Program Planning, 30, 325-338. http://dx.doi.org/10.1016/j.evalprogplan.2007.08.002

[22] Klein, J.T. (2008) Evaluation of Interdisciplinary and Transdisciplinary Research-A Literature Review. American Journal of Preventive Medicine, 35, S116-S123. http://dx.doi.org/10.1016/j.amepre.2008.05.010

[23] Vajjhala, S., Krupnick, A., McCormick, E., Grove, M., McDowell, P., Redman, C., Shabman, L. and Small, M. (2007) Rising to the Challenge: Integrating Social Science into NSF Environmental Observatories. Resource for the Future Report. http://www.rff.org/rff/news/features/upload/30183_1.pdf

[24] Foster, G.M. (1987) World Health Organization Behavioral Science Research: Problems and Prospects. Social Science \& Medicine, 24, 709-717. http://dx.doi.org/10.1016/0277-9536(87)90107-9

[25] Transdisciplinary Research on Energetics and Cancer (2009) Midcourse Update 39th Regular Meeting of the Board of Scientific Advisors. US HHS National Institute of Health. http://cancercontrol.cancer.gov/brp/trec/docs/TREC_Briefing_Book_508.pdf

[26] Crow, M.M. (2011) Time to Rethink the NIH. Nature, 471, 569-571. http://dx.doi.org/10.1038/471569a

[27] Gragson, T.L. and Grove, M. (2006) Social Science in the Context of the Long Term Ecological Research Program. Society and Natural Resources: An International Journal, 19, 93-100. http://dx.doi.org/10.1080/08941920500394410

[28] Gragson, T.L., Grove, J.M. and Childers, D. (2005) Engaging the Social Sciences to LTER Network-Level Science \& 
Synthesis. http://intranet2.lternet.edu/documents/engaging-social-sciences-lter-network-level-science-synthesis

[29] National Science Foundation (2011) Long-Term Ecological Research Program: A Report of the 30 Year Review Committee. Advisory Committee for the Biological Sciences.

http://intranet2.lternet.edu/content/report-lter-30-year-review-committee-released

[30] Palmer, M.A. (2012) Socioenvironmental Sustainability and Actionable Science. Bioscience, 62, 5-6. http://dx.doi.org/10.1525/bio.2012.62.1.2

[31] National Research Council (2003) Frontiers in Agricultural Research: Food, Health, Environment, and Communities. The National Academies Press, Washington DC.

[32] University of Arkansas (2009) Rice CAP Cumulative Project Report. http://www.ricecap.uark.edu/Management/Annual Reports/Board\%20mtg SanDiegoCA milusJan09.pdf

[33] USDA National Institute of Food and Agriculture (2011) Specialty Crop Research Initiative FY2012 Request for Applications. http://www.nifa.usda.gov/funding/rfas/specialty_crop.html

[34] National Research Council (2009) A New Biology for the 21st Century. The National Academies Press, Washington DC.

[35] USDA National Institute of Food and Agriculture (2009) Climate Change Strategic Directions for NIFA. Washington DC.

[36] Office of Management and Budgets (2011) Memorandum for the Heads of Executive Departments and Agencies. www.whitehouse.gov/.../files/omb/assets/memoranda_2010/m10-30.pdf

[37] National Research Council (2010) Toward Sustainable Agricultural Systems in the 21st Century. The National Academies Press, Washington DC.

[38] Cooperative State Research, Education, and Extension Service (2008) Economics in CSREES: A Report to the Administrator. Washington DC.

[39] USDA National Institute of Food and Agriculture (2010) Social Science Research Planning: Climate Change, Bio-Energy, and Natural Resources Workshop. http://www.nifa.usda.gov/nea/nre/in_focus/ere_if_social_science.html

[40] Regional Approaches to Climate Change_-Pacific Northwest Agriculture (2013) Project Director's Update. https://www.reacchpna.org/project-director-updates/directors-update-may-2013/.

[41] Climate Change, Mitigation, and Adaptation in Corn-Based Cropping Systems [Sustainable Corn]. Top 10 Year 3 Accomplishments. http://www.sustainablecorn.org/

[42] Useful to Usable. Transforming Climate Variability and Change Information for Cereal Crop Producers Accomplishment Highlights, April 2011-February 2013.

https://drinet.hubzero.org/resources/581/download/U2UExecSummary2013_2_7.pdf 